OPEN ACCESS

Edited by:

Cyrus Khandanpour,

University Hospital Münster, Germany

Reviewed by:

Swaminathan P. lyer,

University of Texas MD Anderson

Cancer Center, United States

Eleftherios Spartalis,

National and Kapodistrian University of

Athens, Greece

${ }^{*}$ Correspondence:

Ramin Radpour

ramin.radpour@dbmr.unibe.ch

Adrian F. Ochsenbein

adrian.ochsenbein@insel.ch

Specialty section: This article was submitted to Hematologic Malignancies,

a section of the journal

Frontiers in Oncology

Received: 02 February 2021 Accepted: 22 March 2021

Published: 04 May 2021

Citation:

Radpour R, Stucki M, Riether $C$ and Ochsenbein AF (2021) Epigenetic Silencing of Immune-Checkpoint Receptors in Bone Marrow- Infiltrating

T Cells in Acute Myeloid Leukemia. Front. Oncol. 11:663406. doi: $10.3389 /$ fonc. 2021.663406

\section{Epigenetic Silencing of Immune- Checkpoint Receptors in Bone Marrow- Infiltrating T Cells in Acute Myeloid Leukemia}

\author{
Ramin Radpour ${ }^{1,2 *}$, Miriam Stucki ${ }^{1,2}$, Carsten Riether ${ }^{1,2}$ and Adrian F. Ochsenbein ${ }^{1,2 *}$ \\ 1 Tumor Immunology, Department for BioMedical Research (DBMR), University of Bern, Bern, Switzerland, ${ }^{2}$ Department of \\ Medical Oncology, Inselspital, Bern University Hospital, University of Bern, Bern, Switzerland
}

Background: Immune-checkpoint (IC) inhibitors have revolutionized the treatment of multiple solid tumors and defined lymphomas, but they are largely ineffective in acute myeloid leukemia (AML). The reason why especially PD1/PD-L1 blocking agents are not efficacious is not well-understood but it may be due to the contribution of different IC ligand/receptor interactions that determine the function of T cells in AML.

Methods: To analyze the interactions of IC ligands and receptors in AML, we performed a comprehensive transcriptomic analysis of FACS-purified leukemia stem/progenitor cells and paired bone marrow (BM)-infiltrating $\mathrm{CD} 4^{+}$and $\mathrm{CD} 8^{+} \mathrm{T}$ cells from 30 patients with AML. The gene expression profiles of activating and inhibiting IC ligands and receptors were correlated with the clinical data. Epigenetic mechanisms were studied by inhibiting the histone deacetylase with valproic acid or by gene silencing of PAC1.

Results: We observed that IC ligands and receptors were mainly upregulated in leukemia stem cells. The gene expression of activating IC ligands and receptors correlated with improved prognosis and vice versa. In contrast, the majority of IC receptor genes were downregulated in BM-infiltrating $\mathrm{CD}^{+} \mathrm{T}$ cells and partially in $\mathrm{CD}^{+} \mathrm{T}$ cells, due to pathological chromatin remodeling via histone deacetylation. Therefore, treatment with histone deacetylase inhibitor (HDACi) or silencing of PAC1, as a T cell-specific epigenetic modulator, significantly increased the expression of IC receptors and defined effector molecules in $\mathrm{CD}^{+} \mathrm{T}$ cells.

Conclusions: Our results suggest that $\mathrm{CD} 8^{+} \mathrm{T}$ cells in $\mathrm{AML}$ are dysfunctional mainly due to pathological epigenetic silencing of activating $\mathrm{IC}$ receptors rather than due to signaling by immune inhibitory $I C$ receptors, which may explain the limited efficacy of antibodies that block immune-inhibitory ICs in AML.

Keywords: acute myeloid leukemia, immune-checkpoints, immunotherapy, leukemia stem cell (LSC), CD8 ${ }^{+}$cell, $\mathrm{CD}^{+} \mathrm{T}$ cell, epigenetics (chromatin remodelling), histone (de)acetylation 


\section{INTRODUCTION}

Acute myeloid leukemia (AML) is a hematologic malignancy with a poor clinical prognosis. It arises from clonal expansion of oncogene-transformed hematopoietic stem and progenitor cells, known as leukemia stem cells (LSCs) (1). LSCs are therapy resistant and evade direct killing by immune cells due to diverse escape mechanisms. Therefore, LSCs are the leading cause of relapse after initial successful chemotherapy (2).

Immune cells are part of the bone marrow (BM) microenvironment and interact with the leukemia stem/ progenitor cells. Clinical observations and experimental evidence suggest that myeloid leukemia is regulated by the immune system (3). Tumor cells, including LSCs, can suppress effective tumor-specific $\mathrm{T}$ cell responses. LSCs escape the immune control by natural killer (NK) cells and $\mathrm{CD}^{+} \mathrm{T}$ cells through the expression of immune-inhibitory molecules by downregulating of critical molecules/pathways involved in immune recognition, or by the expression of "don't eat me" signals, such as CD47 (4). Immune-checkpoints (ICs) are essential regulators of the immune system, through activation (stimulatory checkpoint molecules) or inhibition (inhibitory checkpoint molecules) of immune cells $(5,6)$. The balance of stimulatory and inhibitory ligand/receptor interaction determines the amplitude and quality of the antigen-specific immune responses (5). The generation of immune-checkpoint inhibitors (ICIs) that blocks the inhibitory IC receptors, such as cytotoxic T-lymphocyte-associated protein 4 (CTLA-4) or programmed cell death protein 1 (PD-1), has revolutionized the treatment of different solid tumors and lymphomas (7). In contrast, blocking ICs in the treatment of leukemia seems less effective (8-10). This is potentially due to $\mathrm{BM}$-infiltrating $\mathrm{T}$ cells expressing other inhibitory receptors, such as $\mathrm{T}$ cell immunoglobulin and mucin-domain containing-3 (TIM-3) and Lymphocyte-activation gene 3 (LAG-3) (11). Indeed, understanding the expression signature of ICs on leukemia stem/progenitors and paired lymphocytes in the $\mathrm{BM}$ is crucial for the development of novel immunotherapy approaches.

In the present study, we performed a comprehensive expression analysis of important IC ligand/receptor pairs in AML stem and progenitor cells in parallel with paired BMinfiltrating lymphocytes. We observed that gene expression of IC ligands and receptors were mainly upregulated in leukemia stem and progenitor cells (LSPCs). A high gene expression of IC ligands and receptors with an activation function or low gene expression of IC ligands and receptors with inhibition function in LSCs correlated with better overall survival. In contrast, the majority of IC receptor genes were downregulated in BMinfiltrating $\mathrm{CD}^{+} \mathrm{T}$ cell and partially in $\mathrm{CD}^{+} \mathrm{T}$ cells. We identified pathological histone deacetylation as the main cause for the downregulation of IC receptors in $\mathrm{CD}^{+}$and $\mathrm{CD} 4^{+} \mathrm{T}$ cells. Therefore, treatment with histone deacetylase inhibitor (HDACi) significantly increased the expression of IC receptors on T cells in AML at both gene and protein levels. Furthermore, the expression of the phosphatase PAC1, a key $\mathrm{T}$ cell-specific epigenetic modulator, negatively correlated with the expression of IC receptors in T cells from AML patients. Consequently, silencing of the $P A C 1$ gene significantly increased the expression of different ICs on $\mathrm{T}$ cells. These findings could have potential implications for the design of immunotherapies that target AML and/or AML LSCs.

\section{MATERIALS AND METHODS}

\section{Patients}

Blood and BM aspirates from patients diagnosed with AML were prospectively collected at the Department of Medical Oncology, University Hospital Bern. Thirty patients were selected from this repository based on the FACS immune-phenotype of the AML cells and the risk category. Risk categories of AML patients were determined according to the defined molecular profile of patients (guidelines for Dutch-Belgian Hemato-Oncology Cooperative Group (HOVON) and Swiss Group for Clinical Cancer Research (SAKK)). BM aspirates performed as a staging procedure in patients with lymphoma that did not have a pathological infiltration in the aspirate nor the biopsy were used as controls.

\section{FACS-Purification of Stem/Progenitors and Paired $\mathrm{CD}^{+} / \mathrm{CD}^{+} \mathrm{T}$ Cells}

LSCs were defined as $\mathrm{CD} 45^{+} \mathrm{Lin}^{-} \mathrm{CD} 90^{-} \mathrm{CD} 38^{-} \mathrm{CD} 34^{+}$, leukemic progenitor cells (LPCs) as $\mathrm{CD} 45^{+} \mathrm{Lin}{ }^{-} \mathrm{CD} 90^{-} \mathrm{CD} 38^{+} \mathrm{CD} 34^{+}$, hematopoietic stem cells (HSCs) as $\mathrm{CD} 45^{+} \mathrm{Lin}^{-} \mathrm{CD} 90^{+} \mathrm{CD} 38^{-}$ $\mathrm{CD} 34^{+}$and normal progenitors (HPCs) as $\mathrm{CD} 45^{+} \mathrm{Lin}^{-}$ $\mathrm{CD} 90^{+} \mathrm{CD} 38^{+} \mathrm{CD} 34^{+}$. CD $4^{+} \mathrm{T}$ lymphocytes were $\mathrm{CD}_{4} 5^{+} \mathrm{Lin}^{+} \mathrm{CD} 4^{+}$. $\mathrm{CD} 8^{+} \mathrm{T}$ lymphocytes were $\mathrm{CD} 45^{+} \mathrm{Lin}^{+} \mathrm{CD} 8^{+}$. Lineage positive cells were defined by the expression of $\mathrm{CD} 2$, CD3e, CD14, CD16, CD19, CD56 or CD235. All cell populations were FACS-purified according to their immunophenotype using a FACS ARIA III (BD Biosciences, USA).

\section{Antibodies and Flow-Cytometry}

$\alpha \mathrm{CD} 2$-biotin (clone: RPA-2.10), $\alpha \mathrm{CD} 14$-biotin (clone: HCD14), $\alpha \mathrm{CD} 16$-biotin (clone: 3G8), $\alpha \mathrm{CD} 19$-biotin (clone: 561), $\alpha \mathrm{CD} 235$ a-biotin (clone: HIR2), $\alpha \mathrm{CD} 3$-biotin (clone: OKT3a), $\alpha$ CD34-APC (clone: 561), $\alpha \mathrm{CD} 38-\mathrm{PE} / \mathrm{Cy} 7$ (clone: HIT2), $\alpha \mathrm{CD} 4-\mathrm{APC} / \mathrm{Cy} 7$ (clone: RPA-T4), $\alpha \mathrm{CD} 8 \mathrm{a}-\mathrm{Pacific}$ Blue (clone: RPA-T8), $\alpha \mathrm{CD} 90-\mathrm{PerCP} / \mathrm{Cy} 5.5$ (clone: 5E10), $\alpha \mathrm{CD} 272-$

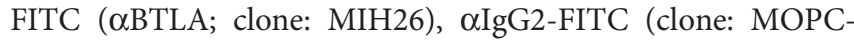
$173), \alpha C D 200 R-P E$ (clone: OX-108), $\alpha$ IgG1-PE (clone: MOPC-21), $\alpha$ CD160-PerCP/Cy5.5 (clone: BY55), $\alpha \operatorname{IgM}-$ PerCP/Cy5.5 (clone: MM-30), $\alpha$ CD96-APC (clone: NK92.39), $\alpha \mathrm{IgG1}$-APC (MOPC-21), $\alpha \mathrm{CD} 28-\mathrm{PE} / \mathrm{Cy} 7$ (clone: CD28.2), $\alpha$ IgG1-PE/Cy7 (MOPC-21) and $\alpha$ Streptavidin-FITC were from BioLegend, USA. $\alpha$ CD 45-PE (clone: HI30) was from eBioscience, USA. $\alpha$ IgG1-PE (clone: IS11-12E4.23.20) was from Miltenyi Biotec, Germany. Samples were analyzed on BD LSRFortessa $^{\mathrm{TM}}$ (BD Biosciences, USA). Data was analyzed using FlowJo software v.10.7 (FlowJo, LLC, USA). 


\section{Molecular Profiling}

To analyze the interactions of IC ligands and receptors in AML, we performed a detailed transcriptomic analysis in FACSpurified leukemia stem/progenitor cells and paired $\mathrm{CD}^{+}$and $\mathrm{CD}^{+} \mathrm{T}$ cells from 30 patients with AML and seven controls. In total, 148 samples from 30 AML patients and seven controls were analyzed using the human expression array "GeneChip ${ }^{\circledR}$ Human Transcriptome Array 2.0 (HTA 2.0)" (Affymetrix Inc., USA). The HTA 2.0 high-resolution array contains $>6.0$ million probes covering both coding and non-coding transcripts. This provides an in-depth insight into all coding and non-coding transcripts by providing the coverage and accuracy required to detect all known transcript isoforms produced by a gene. Of note, 146 samples were selected for further analysis because of insufficient mRNA amplification of two LSCs samples; due to limiting cell numbers (patients \#7 and \#23).

Total RNA was extracted from the FACS-purified samples using RNeasy Micro Kit (QIAGEN, Switzerland). The quantity of extracted RNA was assessed by NanoDrop ND-1000 spectrophotometer (NanoDrop Technologies, Inc., USA) and by Bioanalyzer instrument using the RNA 6000 Pico Chip (Agilent Technologies, Germany). The purified RNA was quantified using the QuantiFluor RNA System (Promega, USA). cDNA was synthesized using the GeneChip ${ }^{\circledR}$ Human Transcriptome Pico Assay 2.0 (Affymetrix Inc., USA). The arrays were hybridized with the biotin-labeled fragments using GeneChip $^{\circledR}$ Hybridization, Wash, and Stain Kit (Affymetrix Inc., USA), and rotated in the hybridization oven for 48 hours at $45^{\circ} \mathrm{C}$ and $60 \mathrm{rpm}$. The arrays were washed and stained with a streptavidin phycoerythrin conjugate on a GeneChip Fluidics 450 Workstations and scanned on a GeneChip Scanner 3000 7G (Affymetrix Inc., USA). The expression data were acquired using the Affymetrix GeneChip Operating Software (GCOS). HTA annotations supplied by Affymetrix were used as probe identifiers.

\section{Transcriptomic Data Analysis}

HTA data analysis was performed after Robust Multi-Array Analysis (RMA), normalization, and log transformation. Differentially expressed genes were defined according to the following criteria: mean intensity greater than three, fold change greater than 1.5 and $P$-values set to $P<0.05$. Principal component analysis (PCA) was used to map the variations among profiled samples. Unsupervised hierarchical clustering of significant upregulated or downregulated genes was applied using the standard Euclidean's method and the heat maps were generated according to the standard normal distribution of the values.

\section{Gene Expression Analyses Using Quantitative RT-PCR (qPCR)}

Several target genes were analyzed by real-time (qRT)-PCR. cDNA was synthesized using a High-Capacity cDNA Reverse Transcription Kit (Applied Biosystems, USA). Primers were designed for each gene by Primer3Plus (http://www. bioinformatics.nl/) or using Primerquest Software (Integrated DNA Technologies). The complete sequences of used primers are listed in Supplementary Table 1. qRT-PCR was performed using FastStart Universal SYBR ${ }^{\circledR}$ Green 2X PCR Master Mix (Roche, Switzerland). Raw values were normalized using the geometric mean of reference genes (ACTB and GAPDH). qRTPCR reactions were performed in replicate using QuantStudio 3 System or ABI Prism 7500 Sequence Detection System (Applied Biosystems).

\section{Gene Set Enrichment Analysis}

Gene set enrichment analysis (GSEA) was performed using GSEA software (Broadinstitute, Cambridge, USA). Enrichment analysis was assessed for 30 IC ligand genes and 30 IC receptor genes, respectively.

\section{Histone Deacetylase Inhibition}

FACS-purified $\mathrm{CD}^{+}$or $\mathrm{CD}^{+} \mathrm{T}$ cells were seeded in 48-well culture plates at a density of $1 \times 10^{5}$ cells/well in IMDM media (Sigma, Switzerland) supplemented with 10\% FCS, 1\% Pen-Strep (Sigma, Switzerland), and hIL-2 5u/ml (Prospect). Cells were treated with $1 \mathrm{mM}$ sodium valproate (VPA) (Sigma, Switzerland) or PBS. Then, $24 \mathrm{~h}$ post treatment, total RNA was extracted and, after cDNA synthesis, qRT-PCR was assessed for a panel of selected genes, as described above. The $\mathrm{CD} 4^{+}$or $\mathrm{CD}^{+} \mathrm{T}$ cells were harvested $48 \mathrm{~h}$ post treatment and FACS-analyzed for the protein expression of selected ICs.

\section{Gene Silencing of PAC1 (DUSP2)}

The human PAC1 gene was silenced in isolated human $\mathrm{CD}^{+}$or $\mathrm{CD}^{+} \mathrm{T}$ cells from BM of AML patients using siRNA according to the manufacturer's instructions (Santa Cruz Biotechnology; cat. sc-39004). Briefly, siPAC1 or siCtrl (scrambled control) was mixed with Lipofectamine LTX (Thermo Fisher Scientific) in serum-free media. Isolated $\mathrm{CD}^{+}$or $\mathrm{CD}^{+} \mathrm{T}$ cells were subsequently treated with transfection complexes in the presence of antibiotic-free growth medium supplemented with $10 \%$ FCS and hIL-2 $5 \mu / \mathrm{ml}$ (Prospect) for $48 \mathrm{~h}$.

\section{Statistical Analysis}

Statistical analysis for qRT-PCR data and functional studies were performed using GraphPad Prism (GraphPad Software, USA). The Shapiro-Wilk test was used to assess the assumption of normality in the datasets. Gene expression data were analyzed using Student's t-test (2-tailed). Survival time differences were plotted using Kaplan-Meier curves and analyzed using the logrank test. The assigned cut-point for the survival analysis was assessed using the X-Tile program based on the mean expression of the immune-checkpoints gene panel. All $P$-values were considered significant when $P<0.05$.

\section{Data Availability and Resources}

All transcriptomic data compiled in this study have been deposited in NCBI GEO under the accession codes: GSE117090. 


\section{RESULTS}

\section{IC Receptors and Ligands Are Upregulated in AML Stem and Progenitors}

The expression of 30 IC ligand/receptor pairs was analyzed in FACS-purified stem and progenitor cells together with paired lymphocytes $\left(\mathrm{CD}^{+}\right.$and $\mathrm{CD}^{+} \mathrm{T}$ cells) from $\mathrm{BM}$ aspirates of 30 patients with newly diagnosed AML. Seven BM aspirates from lymphoma patients without documented infiltration were used as controls (Figure 1A). In total, 146 samples from different cell populations were analyzed. The clinical and molecular characteristics of AML patients are summarized in Table $\mathbf{1}$ and the complete characteristics of AML patients and controls have previously been published by our group (12).

First, we analyzed the expression of 30 defined IC ligand/ receptor genes in LSCs and LPCs as well as in control hematopoietic stem cells (HSCs) and control hematopoietic progenitor cells (HPCs). We grouped the ligands and receptors as activating or inhibitory ICs based on their main reported function, although many ICs have activating or inhibitory functions depending on the cell type and receptor signaling. Principal component analysis (PCA) revealed a distinct gene expression pattern between most LSCs/LPCs compared to the control HSCs/HPCs (Figure 1B). LSCs/LPCs and HSCs/LPCs expressed the majority of the analyzed IC ligand/receptor genes (Figures 1C-F). Ten IC ligands and 11 receptors were significantly upregulated in LSCs/LPCs compared to HSCs/ HPCs. The gene expression of IC ligands and receptors was independent of the AML risk groups (Figure 2 and Supplementary Figure 1). The number of upregulated IC genes in LPCs was higher than in LCSs (Figures 1C, F and Supplementary Figure 2, 3). Gene set enrichment analysis (GSEA) of the 30 analyzed IC ligand/receptor pairs confirmed the upregulation of IC ligands and receptors (Figures 1D, G). Interestingly, many upregulated genes in LSCs/LPCs encode for the IC ligands/receptors with an inhibitory function (e.g., CD200, CD276, IDO1, PDCD1LG2, TDO2, VTCN1, CD96, CD160, CTLA4 and HAVCR2). A high gene expression of IC ligands/ receptors with an activation function or a low expression of ICs with inhibitory function in LSCs correlated with improved overall survival (Figure 1E). A similar trend was observed for IC genes expressed on LPCs without reaching significance (Supplementary Figure 3B).

\section{IC Ligands Are Upregulated While Receptors Are Downregulated in BM-Infiltrating T Cells}

Next, we analyzed the IC gene expression profile of $\mathrm{CD}^{+}$and $\mathrm{CD}^{+} \mathrm{T}$ cells in the BM (Figure 3). The PCA analysis revealed a distinct gene expression pattern between $\mathrm{BM}$-infiltrating $\mathrm{CD} 4^{+}$ and $\mathrm{CD}^{+} \mathrm{T}$ cells in leukemia as compared to the controls (Figure 3A). Six out of 30 IC ligand genes and three of 30 IC receptor genes were differentially expressed in $\mathrm{CD}^{+} \mathrm{T}$ cells of leukemia patients (Figures 3B, C and Supplementary Figure 4). In $\mathrm{CD}^{+} \mathrm{T}$ cells from leukemia patients, 17 of 30 ligands and 10 of 30 receptors were differentially expressed. IC ligand genes were preferentially upregulated, whereas, the receptor genes were mainly downregulated in $\mathrm{CD}^{+} \mathrm{T}$ cells from AML patients (Figures 3D, E, Supplementary Figure 5). Similarly, a high gene expression of ICs with either activating function or a low expression of IC genes with inhibitory function in $\mathrm{CD}^{+} \mathrm{T}$ cells of AML patients correlated with improved overall survival (Figure 3F). In contrast, the expression of IC genes in $\mathrm{CD} 4^{+} \mathrm{T}$ cells was not a prognostic marker (Supplementary Figure 4B).

\section{IC Receptors in AML BM-Infiltrating T Cells Are Silenced Due to Pathological Histone Deacetylation}

Since IC receptor genes were predominantly downregulated in $\mathrm{CD}^{+} \mathrm{T}$ cells of AML patients, we postulated that this phenomenon may potentially be due to chromatin remodeling. Previously, we documented a general downregulated gene signature in $\mathrm{BM}$ derived $\mathrm{CD}^{+} \mathrm{T}$ cells in $\mathrm{AML}$ and an upregulation of genes regulating chromatin organization or negatively regulating gene expression and transcription (12). In addition, chromosomal position-based gene-mapping (Karyogram) analysis predicted that downregulated genes were mainly enriched in defined genome regions as indicative of aberrant histone deacetylation (12). In $\mathrm{CD}^{+} \mathrm{T}$ cells, Karyogram analysis of IC receptors revealed that the majority of downregulated IC receptor genes (BTLA, CD27, CD96, CD160, CD200R1, and CD244) were localized in the predicted hotspots for histone remodeling. In contrast, upregulated IC receptor genes or those that were similarly expressed in AML patients and controls, were distributed in other chromosomal regions (Figure 4A).

To assess the impact of histone deacetylation on the gene expression of downregulated IC receptors at functional levels, FACS-purified $\mathrm{CD}^{+}$or $\mathrm{CD}^{+}{ }^{+} \mathrm{T}$ cells from different AML patients with downregulated gene expression of IC receptors were treated with the histone deacetylase inhibitor (HDACi), Valproic acid (VPA). Treatment with VPA significantly increased the expression of IC receptors at both mRNA and protein levels (Figures 4B, C, Supplementary Figure 6). In addition, VPA treatment increased the gene expression of granzyme A (GZMA), granzyme B $(G Z M B)$, interferon-gamma (IFNG), and PDCD1 in $\mathrm{CD} 8^{+} \mathrm{T}$ cells (Figure 4D).

The phosphatase of activated cells 1 (PAC1; also known as dual specificity phosphatase 2, DUSP2) was recently identified as a $\mathrm{T}$ cell suppressor and a crucial epigenetic immune regulator that acts via the histone-deacetylase complex leading to chromatin remodeling of effector $\mathrm{T}$ cells (13). In our AML patient cohort, PAC1 gene expression negatively correlated with the gene expression of downregulated IC receptors, particularly in $\mathrm{CD}^{+} \mathrm{T}$ cells and partially in $\mathrm{CD}^{+} \mathrm{T}$ cells (Figures 5A, B). To assess the functional role of $P A C 1$ on the expression of downregulated IC receptors, we silenced the PAC1 gene in FACS-purified $\mathrm{CD} 8^{+}$or $\mathrm{CD} 4^{+} \mathrm{T}$ cells from AML patients with downregulated gene expression signature of IC receptors. Knockdown of $P A C 1$ gene resulted in a significant upregulation of different IC genes (Figures 5C, D). Importantly, in $\mathrm{CD}^{+} \mathrm{T}$ cells, knockdown of PAC1 led to a significant upregulation of 
A

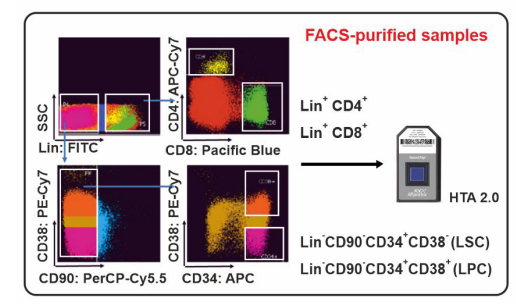

C

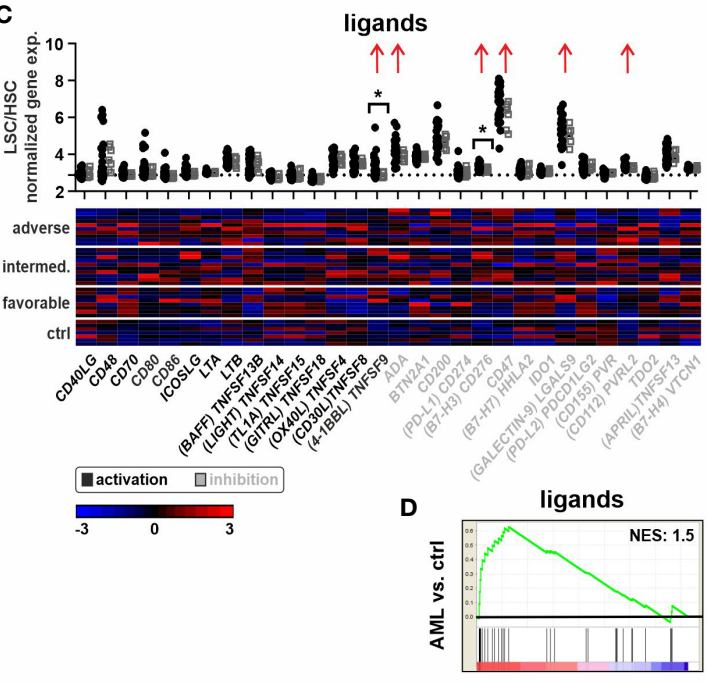

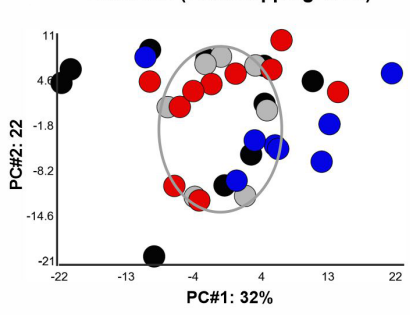

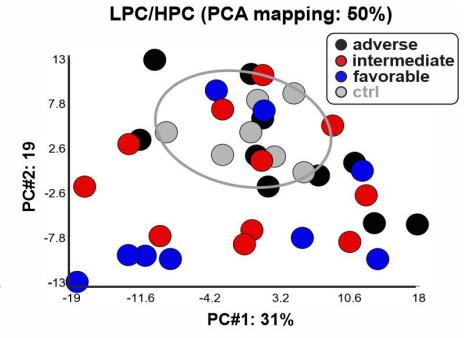

receptors

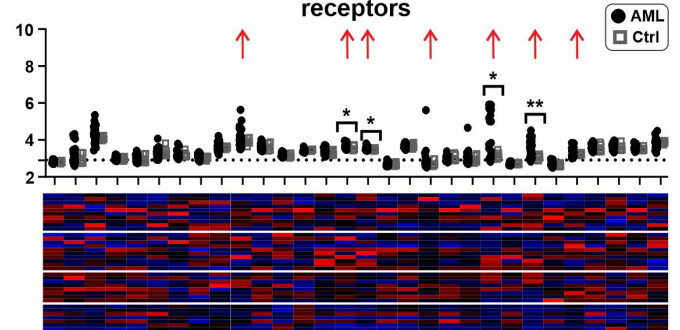

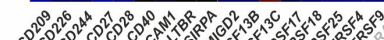
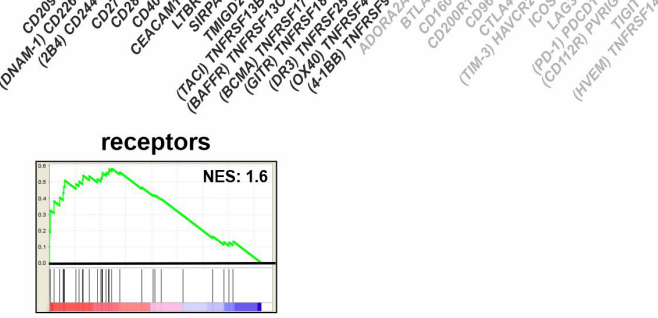

E

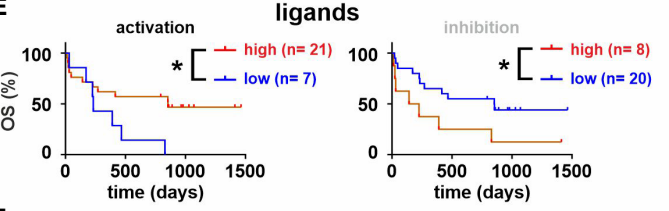

$\mathbf{F}$

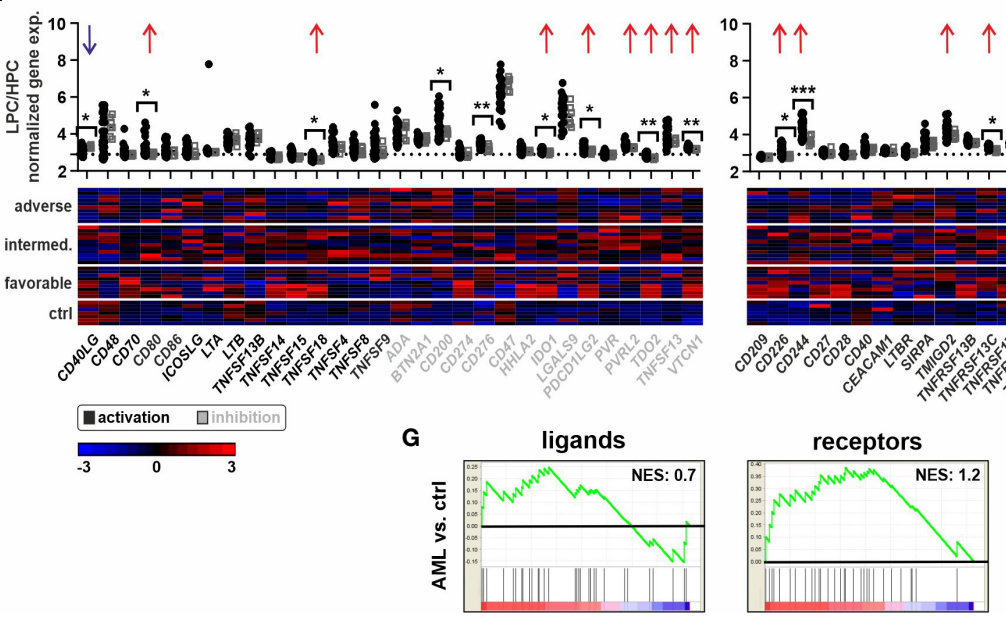

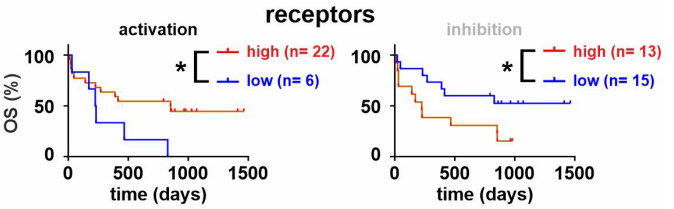

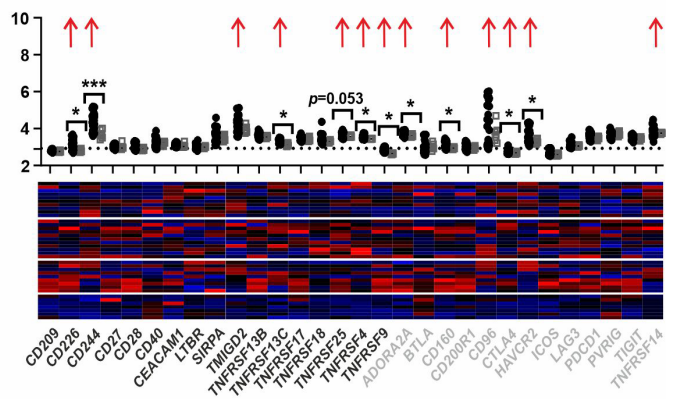

FIGURE 1 | Expression of ICs in AML stem and progenitor cells. (A) Experimental setup. Leukemia stem or progenitor cells (LSCs/LPCs), control hematopoietic stem or progenitor cells (HSCs/HPCs), and paired T cells were FACS-purified. (B) PCA of LSCs/HSCs and LPCs/HPCs from AML patients and controls. (C) Gene expression patterns of ICs in AML LSCs compared to controls (30 ligands and 30 receptors). Dot plots show the gene expression profiles (red arrows showing upregulated ICs and blue arrows indicating downregulated ICs; Fold difference $\geq 1$.3). Heatmaps illustrate the expression patterns in respective AML risk groups. (D) Gene set enrichment analysis (GSEA) representing the normalized enrichment score (NES) of IC gene sets on LSCs (AML vs. ctr). (E) Kaplan-Meier plots of overall survival (OS) for AML patients in the study cohort according to the gene expression signature of activating or inhibitory ICs in LSCs. (F) Gene expression patterns of ICs in AML LPCs compared to controls. Dot plots show the gene expression profiles and heatmaps illustrate the expression patterns in respective AML risk groups. (G) GSEA representing the NES of IC gene sets on LPCs (AML vs. ctrl). Statistics: student's t-test and log-rank test. ${ }^{*} P<0.05,{ }^{* *} P<0.01,{ }^{* * *} P<0.001$. 
TABLE 1 | Clinical and molecular characteristics of AML patients in the present study.

\begin{tabular}{|c|c|c|c|c|c|c|}
\hline Patient ID & Sex & Age (year) & AML risk category & Molecular diagnostic & Cytogenetics & BMblasts (\%) \\
\hline AML\#1 & $\mathrm{M}$ & 46 & Adverse & FLT3-ITD & Normal & 95 \\
\hline AML\#2 & $M$ & 66 & Adverse & FLT3-ITD & Normal & 90 \\
\hline AML\#3 & $\mathrm{F}$ & 49 & Adverse & FLT3-ITD & Normal & 97 \\
\hline AML\#4 & $M$ & 76 & Intermediate & FLT3-ITD, NPM1 & Normal & 70 \\
\hline AML\#5 & $\mathrm{F}$ & 65 & Intermediate & FLT3-ITD, NPM1 & Normal & 90 \\
\hline AML\#6 & $\mathrm{F}$ & 71 & Intermediate & FLT3-ITD, NPM1 & Normal & 60 \\
\hline AML\#7 & $\mathrm{F}$ & 63 & Favorable & NPM1 & Normal & 90 \\
\hline AML\#8 & $M$ & 54 & Favorable & NPM1 & Normal & 20 \\
\hline AML\#9 & $\mathrm{F}$ & 80 & Favorable & NPM1 & Normal & 90 \\
\hline AML\#10 & $\mathrm{F}$ & 66 & Favorable & AML1-ETO & $t(8 ; 21)$ & 90 \\
\hline AML\#11 & $\mathrm{F}$ & 40 & Favorable & AML1-ETO & $\mathrm{t}(8 ; 21)$ & 70 \\
\hline AML\#12 & $M$ & 69 & Adverse & MLL-Rearrangement & Trisomy 11q23.3 & 80 \\
\hline AML\#13 & M & 39 & Intermediate & MLL-Rearrangement & $\mathrm{t}(11 ; 17)(\mathrm{q} 23 ; \mathrm{q} 12-21)$ & 95 \\
\hline AML\#14 & M & 32 & Favorable & $\mathrm{CBFB} / \mathrm{MYH11}$ & $\operatorname{inv}(16)$ & 90 \\
\hline AML\#15 & M & 73 & Favorable & CBFB/MYH11 & $\operatorname{inv}(16)$ & 90 \\
\hline AML\#16 & $\mathrm{F}$ & 30 & Favorable & CEPBA & Normal & 40 \\
\hline AML\#17 & $\mathrm{F}$ & 46 & Intermediate & JAK2 & Trisomy 8 & 90 \\
\hline AML\#18 & $\mathrm{F}$ & 57 & Adverse & Normal & CK & 40 \\
\hline AML\#19 & M & 79 & Adverse & Normal & $\mathrm{t}(4 ; 8)(\mathrm{q} 21 ; \mathrm{q} 22)$, del(9)(p21), del(18)(q21) & 95 \\
\hline AML\#20 & M & 60 & Intermediate & Normal & Trisomy 13 Trisomy 21 & 80 \\
\hline AML\#21 & M & 70 & Intermediate & Normal & Normal & 80 \\
\hline AML\#22 & M & 69 & Adverse & Others & Monosomy 7 (total), 5q31.2 and 5q33 & 85 \\
\hline AML\#23 & $\mathrm{M}$ & 59 & Intermediate & Normal & Normal & 70 \\
\hline AML\#24 & $\mathrm{F}$ & 40 & Adverse & Others & $\mathrm{CK}$ & 90 \\
\hline AML\#25 & $\mathrm{M}$ & 69 & Adverse & Normal & CK with Monosomy 5q,7, 14, 15, 16, 18 & 80 \\
\hline AML\#26 & M & 40 & Favorable & Normal & $\mathrm{t}(15,17)$ & 90 \\
\hline AML\#27 & $\mathrm{F}$ & 75 & Intermediate & Normal & Normal & 20 \\
\hline AML\#28 & M & 59 & Adverse & Normal & Monosomy 7q31.2 & 80 \\
\hline AML\#29 & $\mathrm{F}$ & 20 & Intermediate & Normal & Normal & 60 \\
\hline AML\#30 & M & 70 & Intermediate & Normal & Normal & 70 \\
\hline
\end{tabular}

$B M$, bone marrow; $C K$, complex karyotype.

GZMB and IFNG genes suggesting an improved functionality of $\mathrm{CD}^{+} \mathrm{T}$ cells (Figure 5E).

These findings indicate that silenced expression of IC receptors in AML BM-infiltrating $\mathrm{T}$ cells is mainly due to pathological histone deacetylation and can be reversed by treatment with deacetylation inhibitor agents or by blocking the T cell-specific epigenetic regulator PAC1 (Figure 5F).

\section{DISCUSSION}

Dysfunctional and/or immunosuppressive T cells in AML have been previously described, specifically in peripheral blood (1418). AML LSCs express different co-stimulatory and coinhibitory ligands, and the efficacy of ICIs is identifiably lower in leukemia than in solid tumors (11). Although the role of the PD-1/PD-L1 pathway in immune evasion has been reported in several murine leukemia models (19-21), clinical trials with PD1 blocking antibodies as monotherapy have revealed a low response rate in patients. Several studies with different PD-1 blocking antibodies are ongoing, either at a time point when most of the leukemia bulk has been eliminated prior to chemotherapy, in combination with chemotherapy, or in combination with hypomethylating agents that upregulate the expression of PD-L1 on leukemia cells (11). In addition, trispecific antibodies that combine $\mathrm{T}$ cell redirection to $\mathrm{CD} 33$ expressing myeloid cells together with an anti-PD-L1 part demonstrate enhanced cytotoxicity against primary AML cells in vitro (22). Non responding patients to PD-1 blockade, often co-express other immune inhibitory receptors, such as TIM-3 and LAG-3 on effector T cells (11). Furthermore, AML blasts expressing $\mathrm{T}$ cell inhibitory ligands B7-H3, galectin-9 (Gal-9), and CD200. The expression of most of these ligands is not limited to a given FAB subtype. However, TP53-mutated AML more frequently expresses PD-L1 and 4-1BBL (23).

Leukemia cells do not only express ligands for immunecheckpoints that regulate the leukemia-specific immune response but also express immune-checkpoint receptors (24). This implies that niche cells (including immune cells) that express ligands for these co-stimulatory or co-inhibitory receptors, may regulate LSC function (25). The exact mechanism of how the expression of these co-stimulatory molecules induces AML disease progression and poor prognosis remains unclear. To analyze the interactions of IC ligands and receptors in AML, we performed a detailed gene expression analysis in well-defined samples of FACS-purified leukemia stem/progenitor cells and paired BM-infiltrating $\mathrm{CD}^{+}$ and $\mathrm{CD}^{+} \mathrm{T}$ cells from AML patients and controls.

Our data indicate that ICs are dysregulated on AML LSCs/ LPCs as well as in BM-infiltrating T cells. This promotes multiple interactions between the individual cell populations, leukemia, and immune cells. IC receptor and ligand genes were mainly upregulated in LSCs and LPCs. Some of these ICs, such as CTLA-4, LAG-3, CD27, LTbr, TIM-3, and its ligand Gal-9 or 
A

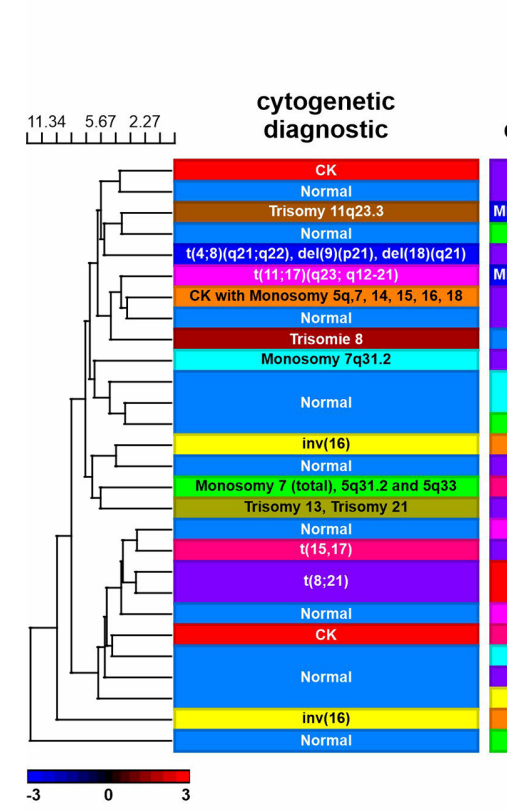

B

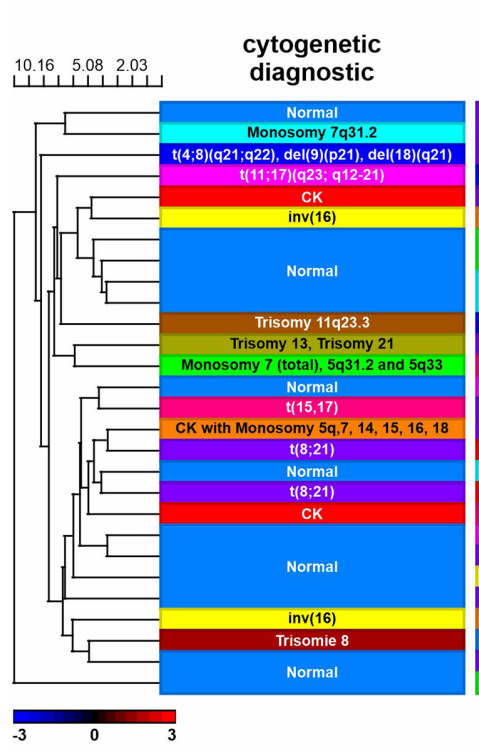

IC ligands (LSC)

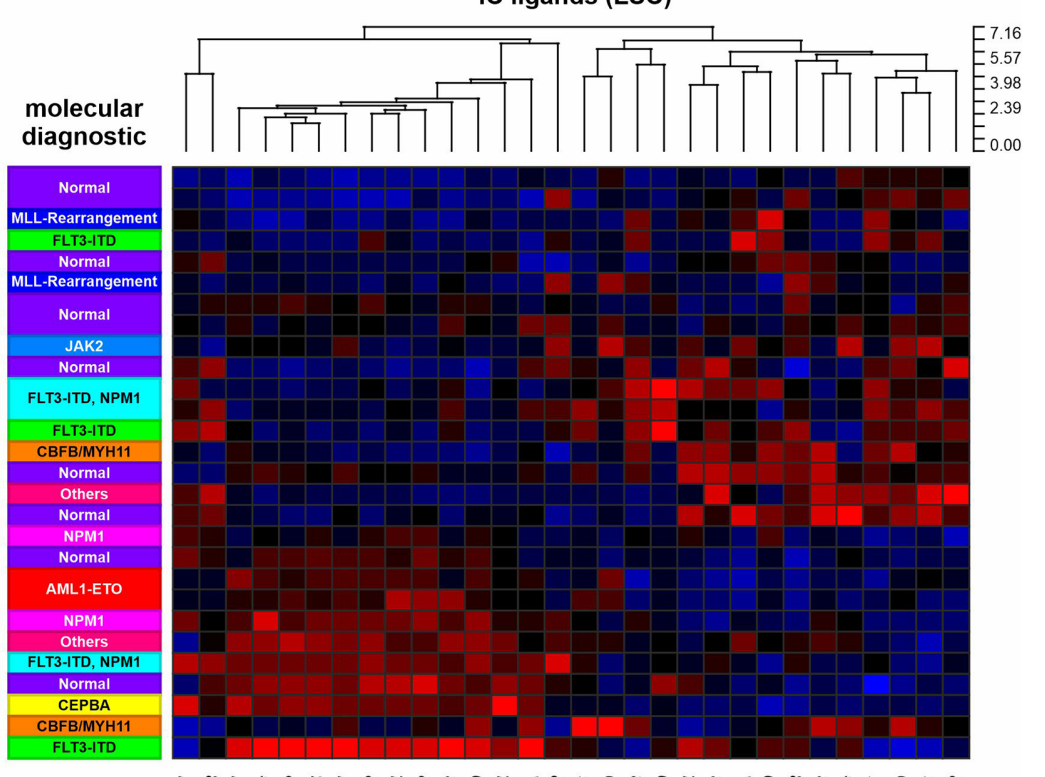

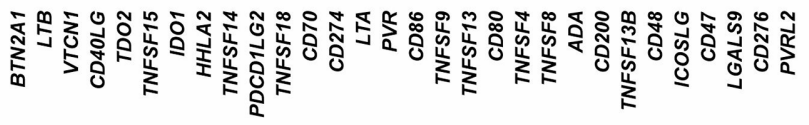

IC receptors (LSC)

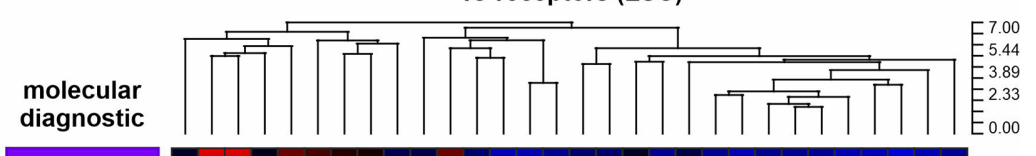

\begin{tabular}{|c|}
\hline Normal \\
MLL-Rearrangement \\
Normal \\
CBFB/MYH11 \\
\hline FLT3-IT \\
\hline FLT3-ITD, NPM1 \\
\hline MLL-Rearrangement \\
Normal \\
Others \\
NPM1 \\
Normal \\
AML1-ETO \\
\hline FLT3-ITD, NPM1 \\
\hline AML1ETO \\
Others \\
NPM1 \\
Normal \\
\hline CEPBA \\
\hline Normal \\
\hline CBFBMYM11 \\
JAK2 \\
Normal \\
FLT3-ITD \\
\hline
\end{tabular}

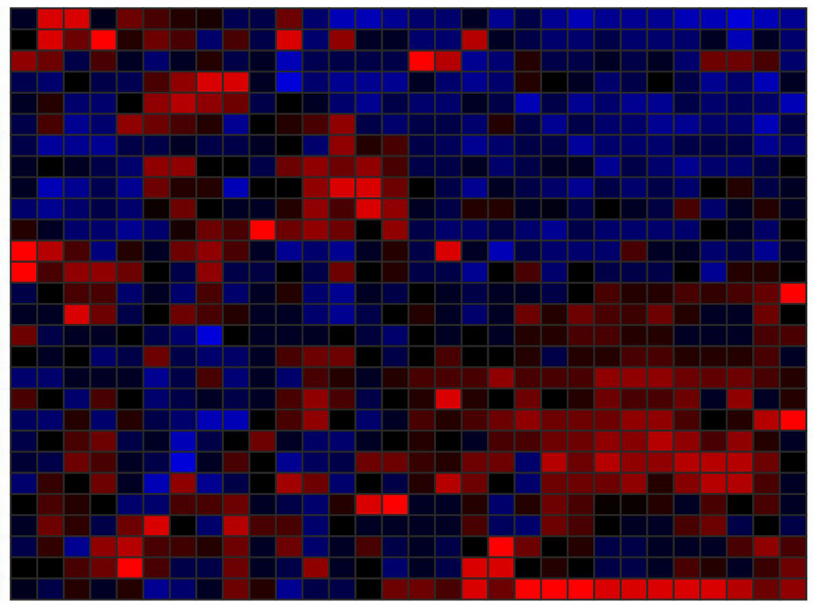

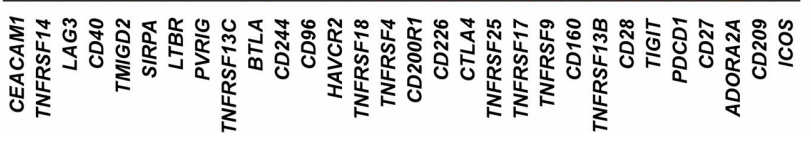

FIGURE 2 | IC expression in LSCs in AML patients with different molecular or cytogenetic aberrations. (A) Heatmap indicating the gene expression profile of 30 IC ligands. (B) Heatmap indicating the gene expression profile of $30 \mathrm{IC}$ receptors.

co-stimulatory molecules, like CD80, CD86, CD40, have been shown to expand LSCs and contribute to disease progression (26-28). In the present study, we did not analyze the role of individual ICs but rather grouped the ligands and receptors as activating or inhibitory ICs based on their main reported function, mainly in T cells (5). However, the function of ICs activation vs. inhibition depends on the cell type and the context of the signaling $(5,29,30)$. Interestingly, the gene expression of activating IC ligands and receptors correlated with improved survival of AML patients, whereas, the gene expression of 

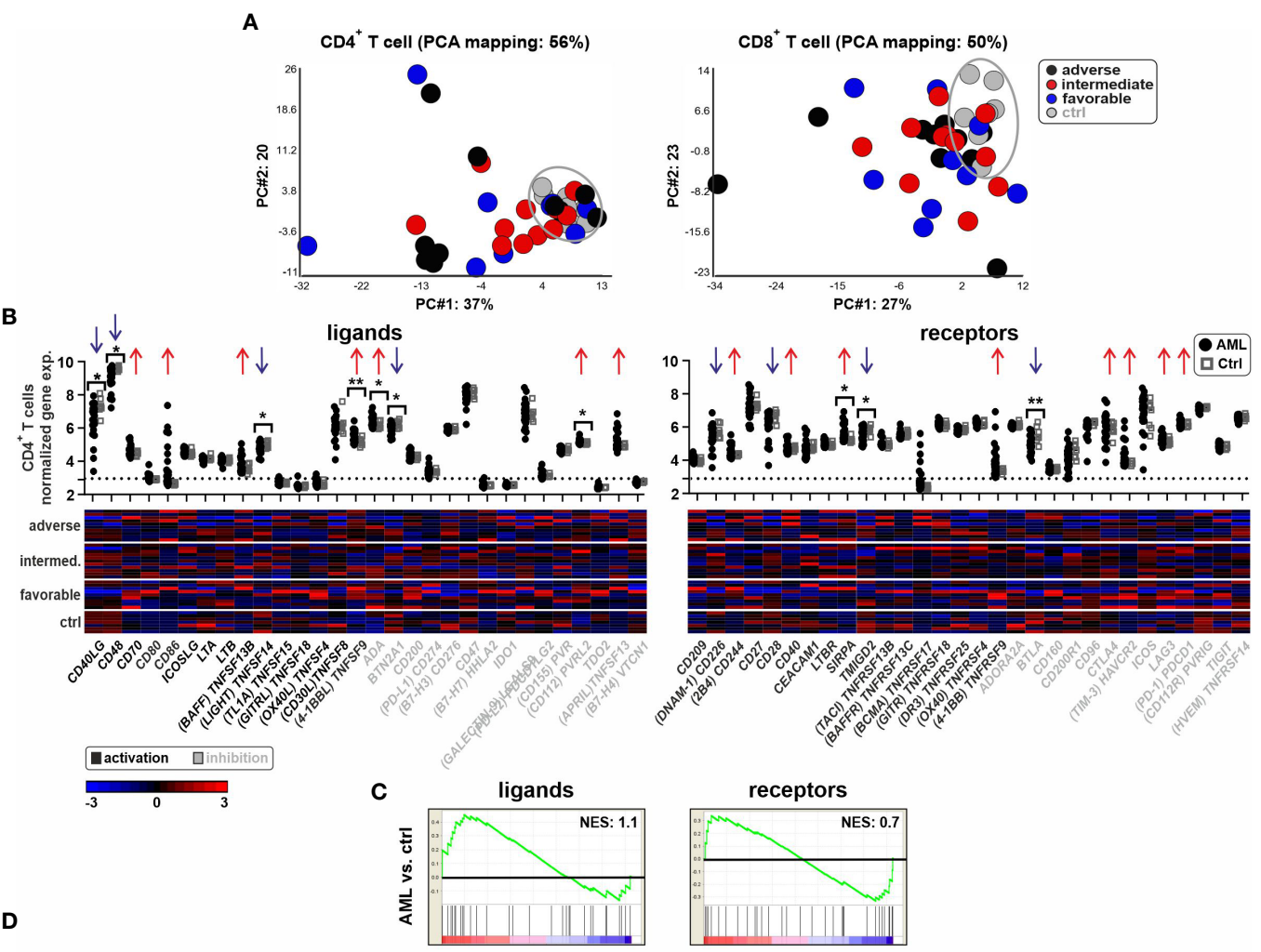

D
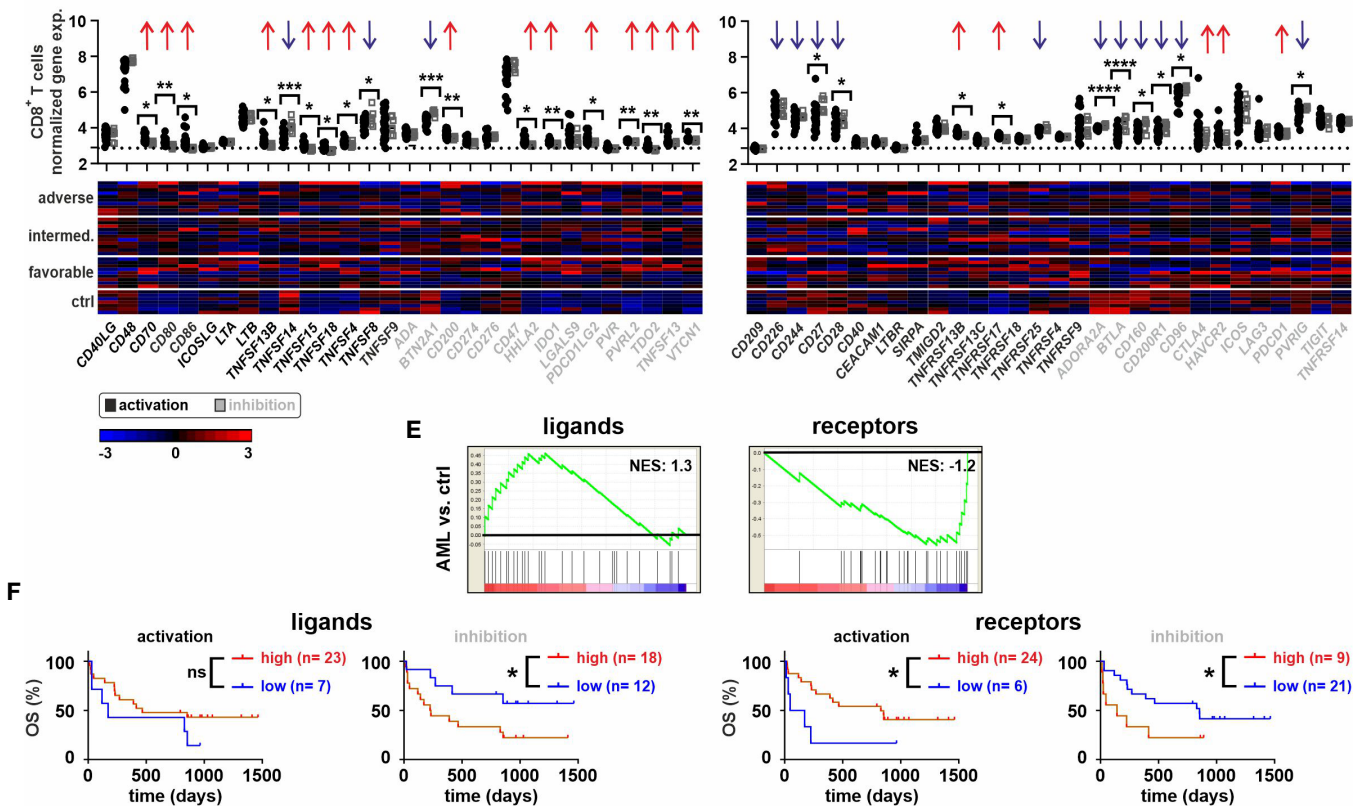

FIGURE 3 | Expression of ICs in BM-derived T cells. (A) PCA of CD4 ${ }^{+}$or CD8 ${ }^{+}$T cells from AML patients and controls. (B) Gene expression patterns of ICs in CD4 T cells from leukemia patients compared to controls (30 ligands and 30 receptors). Dot plots indicate the gene expression profiles (red arrows showing upregulated ICs and blue arrows indicating downregulated ICs; Fold difference $\geq 1$.3). Heatmaps illustrated the gene expression patterns in respective AML risk groups.

(C) GSEA representing the normalized enrichment score (NES) of IC gene sets on CD4 ${ }^{+} \mathrm{T}$ cells (AML vs. ctrl). (D) Gene expression patterns of ICs in CD8 ${ }^{+} \mathrm{T}$ cells from leukemia patients compared to controls. Dot plots show the gene expression profiles and heatmaps illustrate the expression patterns in respective AML risk groups. (E) GSEA representing the NES of IC gene sets on CD8 ${ }^{+} \mathrm{T}$ cells (AML vs. ctrl). (F) Kaplan-Meier plots of overall survival (OS) for AML patients in the study cohort according to the gene expression signature of activating or inhibitory ICs in CD8 ${ }^{+} T$ cells. Statistics: student's t-test and log-rank test. ${ }^{*} P<0.05$, ${ }^{\star \star} P<0.01$, ${ }^{\star \star \star} P<0.001,{ }^{\star \star \star \star} P<0.0001$, ns, not significant. 


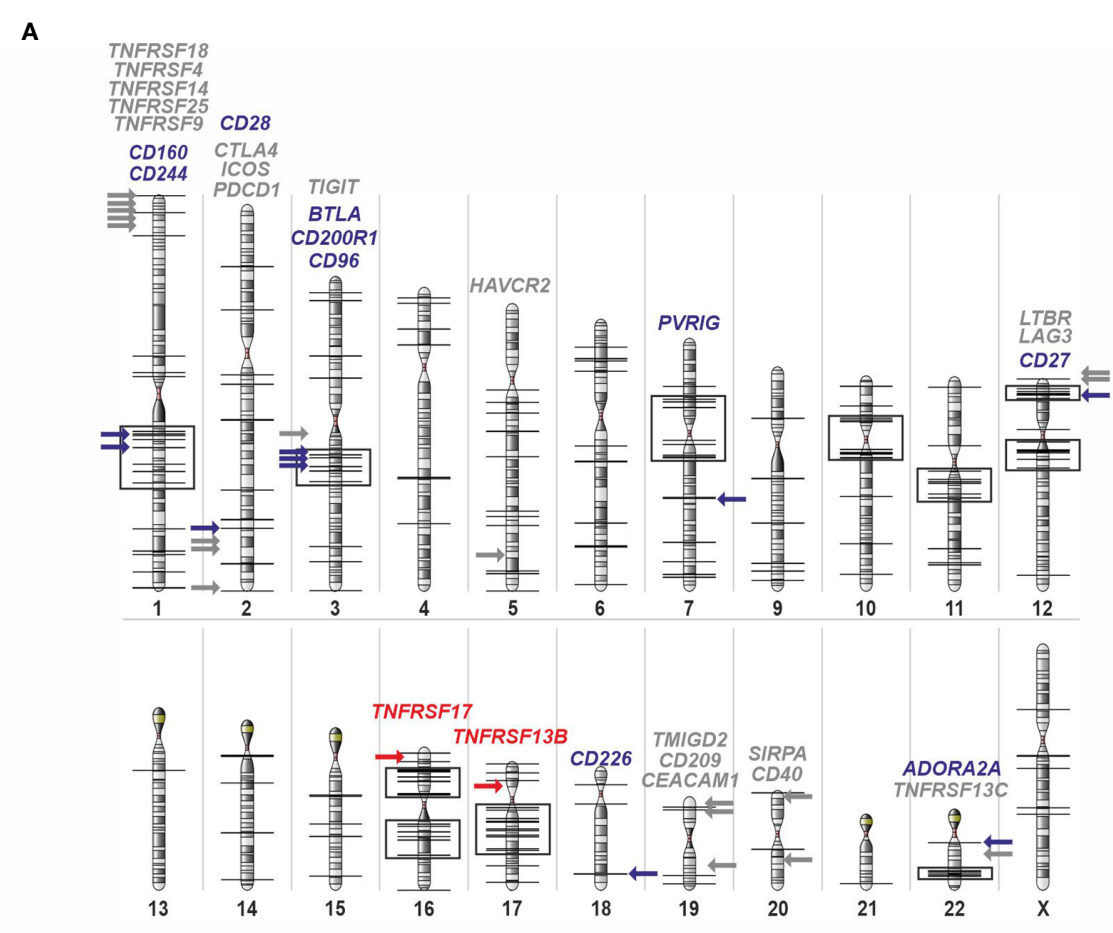

B

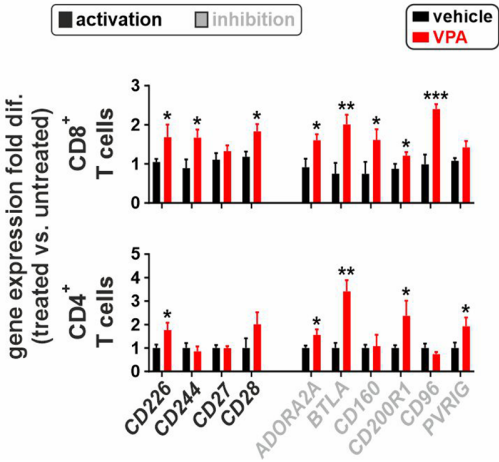

C

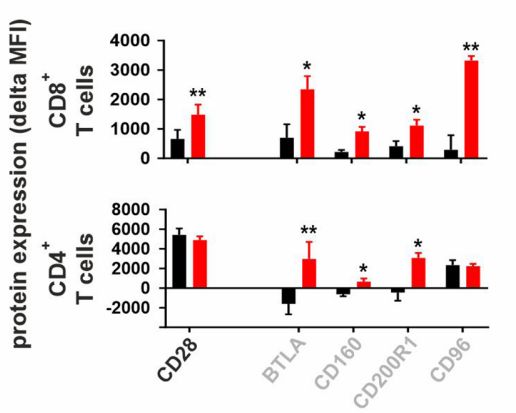

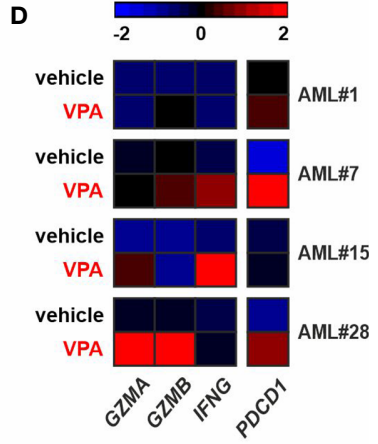

FIGURE 4 | Epigenetic silencing of immune-checkpoint receptors in BM-infiltrating T cells. (A) Chromosomal position-based gene-mapping (Karyogram) analysis indicating the localization of $30 \mathrm{IC}$ receptors. Black vertical lines on the chromosomal surfaces are indicating the previously identified downregulated genes in $\mathrm{CD} 8^{+} \mathrm{T}$ cells that were enriched in particular chromosomal regions mainly due to histone deacetylation (12). Black boxes indicate the chromosomal regions containing at least 5 downregulated genes located in a genome distance with less than $5 \mathrm{Mbp}$ from each other, as potential hotspots for the histone remodeling. The 30 newly analyzed IC receptors of $\mathrm{AML} C D 8^{+} \mathrm{T}$ cells are plotted and highlighted with colored arrows in the karyogram to assess their chromosomal localizations (downregulated ICs: blue arrows; upregulated ICs: red arrows; ICs with no change: gray arrows). (B) Gene expression profile of 10 downregulated IC receptors in $\mathrm{CD}^{+}$or $\mathrm{CD} 4^{+} T$ cells of AML patients upon treatment with VPA. The fold differences were calculated as the ratio of VPA vs. vehicle conditions ( $\mathrm{n}=5 \mathrm{AML}$ patients per each group of $C D 8^{+} T$ cells and $n=4 \mathrm{AML}$ patients per each group of $\mathrm{CD} 4^{+} \mathrm{T}$ cells). (C) Surface protein expression of IC receptors on $\mathrm{CD} 8^{+}$or $\mathrm{CD} 4^{+} \mathrm{T}$ cells of $\mathrm{AML}$ patients. Delta MFI: MFI staining - MFI isotype ( $n=4$ AML patients per group). (D) Heatmap illustrates the expression patterns of three key genes regulating the function of $C D 8^{+} T$ cells as well as $P D C D 1$ gene expression, upon treatment with VPA ( $n=4$ AML patients). Statistics: student's t-test. ${ }^{*} P<0.05$, ${ }^{* *} P<0.01$, ${ }^{\star \star \star} P<0.001$.

inhibitory IC ligands or receptors was a negative prognostic factor. The comparison to control HSC/HSPCs revealed that mainly inhibitory ligand genes were upregulated. This suggests that the sum of the inhibitory signals provided to $\mathrm{T}$ cells diminishes the anti-leukemic immune response. This inhibitory microenvironment in the bone marrow may be further increased by the expression of most of the inhibitory IC ligands, including, PD-L1 on BM-infiltrating $\mathrm{CD} 8^{+} \mathrm{T}$ cells.
However, we observed a strong downregulation of most IC receptor genes on $\mathrm{BM}$-infiltrating $\mathrm{CD}^{+} \mathrm{T}$ cells, possibly reducing the ligand/receptor interaction. PD1 seems to be one exception and Daver et al. recently reported that the frequency of $\mathrm{PD}^{+} / \mathrm{CD}^{+} \mathrm{T}$ cells was significantly higher in bone marrow aspirates (BMAs) of patients with newly diagnosed AML than in healthy BMAs as controls. A similar but not significant difference was observed for the frequency of $\mathrm{OX} 40^{+} / \mathrm{CD}^{+} \mathrm{T}$ cells (23). 
A

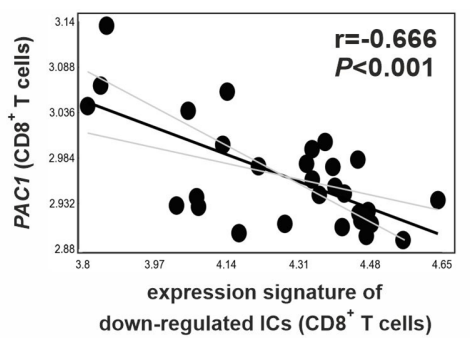

C

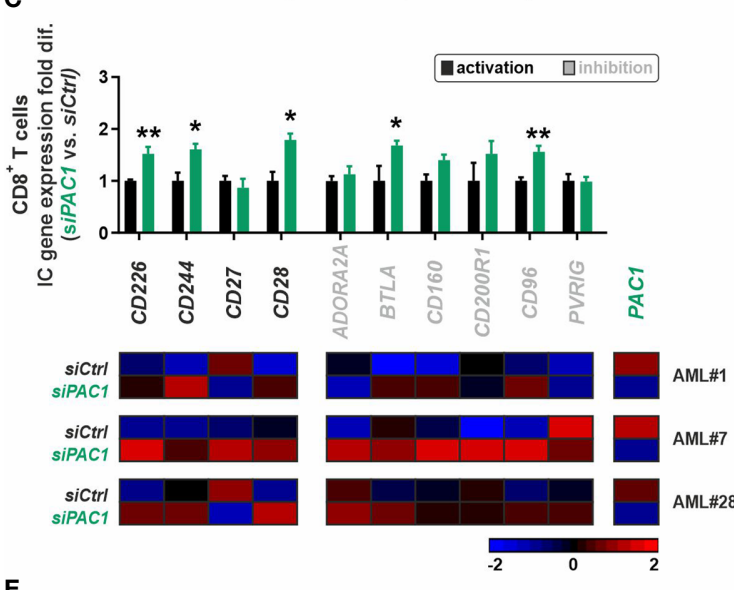

E

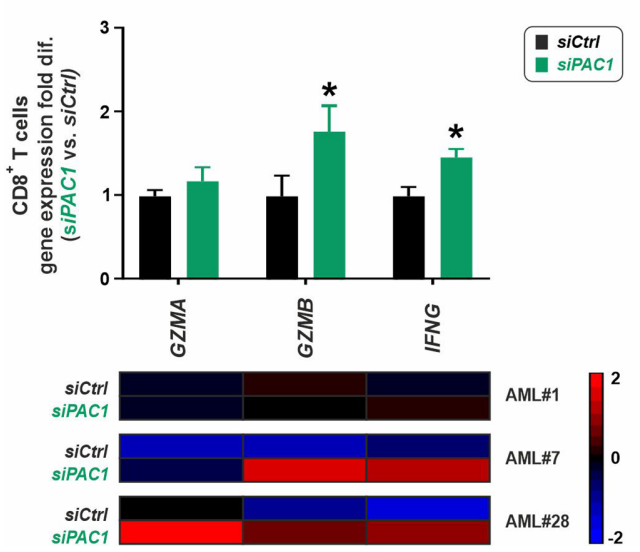

B

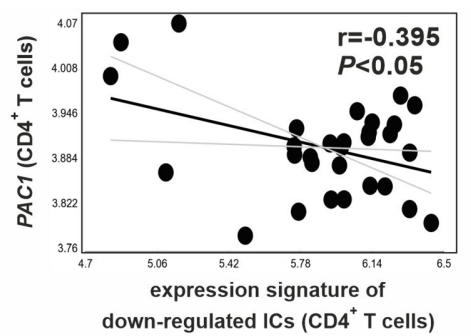

D

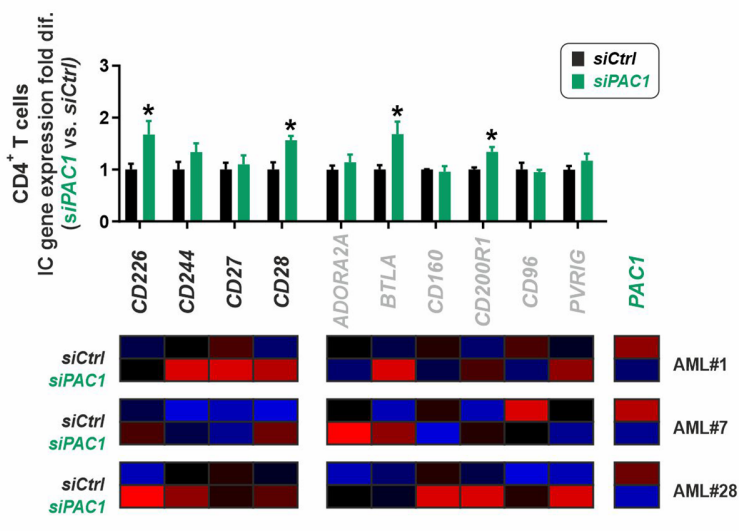

$\mathbf{F}$

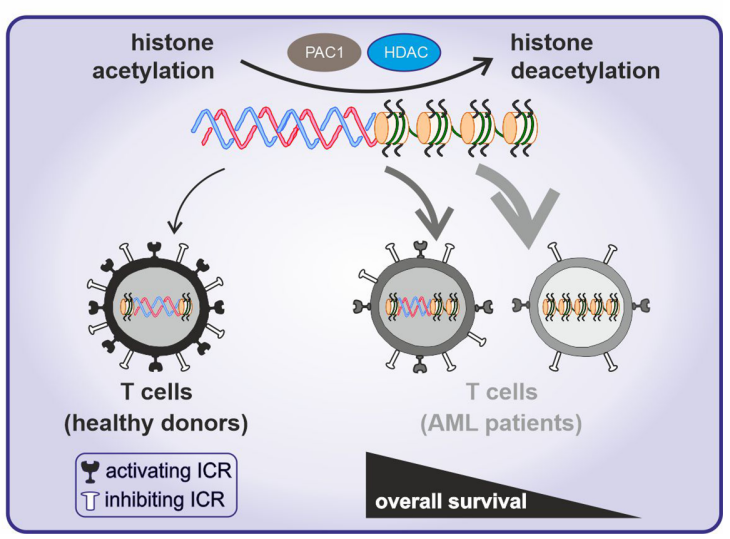

FIGURE 5 | Epigenetic silencing of immune-checkpoint receptors in T cells is modulated via PAC1. (A, B) Correlation analysis of the gene expression signature for downregulated ICs vs. expression pattern of PAC1 gene, in $\mathrm{CD}^{+}$or $\mathrm{CD} 4^{+} \mathrm{T}$ cells respectively ( $\mathrm{n}=30 \mathrm{AML}$ patients). (C, D) Gene expression profile of 10 downregulated IC receptors in $\mathrm{CD} 8^{+}$or $\mathrm{CD} 4^{+} \mathrm{T}$ cells of $\mathrm{AML}$ patients upon $P A C 1$ gene silencing. The fold differences were calculated as the ratio of siPAC1 vs. siCtrl ( $n=3$ AML patients per each group of $C D 8^{+}$or $C D 4^{+} T$ cells). (E) Expression profile of key effector molecules of $C D 8^{+} T$ cells upon PAC1 gene knockdown ( $n=3$ AML patients). (F) BM-infiltrating T cells in AML are dysfunctional due to a downregulation of activating IC receptors mainly via a pathologic epigenetic silencing through histone deacetylation; ICR, immune checkpoint receptor; HDAC, histone deacetylase. Statistics: student's t-test. ${ }^{*} P<0.05,{ }^{* *} P<0.01$.

Comparably, some IC receptors, including $\mathrm{PD}-1$, were upregulated in $\mathrm{CD}^{+}$or $\mathrm{CD}^{+} \mathrm{T}$ cells of $\mathrm{AML}$ patients versus healthy controls in the present study.

Different studies have demonstrated that aberrant epigenetic alterations, such as histone remodeling and DNA methylation play a crucial role in the dysregulation of ICs during carcinogenesis $(14,15,31)$. In addition, DNA hypomethylating agents (HMAs) such as azacitidine and decitabine upregulate the expression of PD-L1 in solid tumors (16) and AML (17) and thereby dampen the anti-tumor immune response. A clinical study testing the combination of azacytidine in combination with the PD-1 blocking antibody nivolumab in the treatment of AML resulted in an overall response rate of 33\% (58\% for the HMAnaive patients (18)). We recently documented that pathological epigenetic alteration via histone deacetylation silences gene expression in $\mathrm{BM}$-infiltrating $\mathrm{CD}^{+} \mathrm{T}$ cells. This silenced gene expression was a positive prognostic factor and $\mathrm{CD}^{+} \mathrm{T}$ cells supported the maintenance and expansion of (12). This finding was somewhat counterintuitive, as activated $\mathrm{CD}^{+} \mathrm{T}$ cells are necessary to eliminate LSCs. The preferential downregulation of 
IC receptors in AML BM-infiltrating $\mathrm{CD}^{+} \mathrm{T}$ cells suggests that they are regulated by epigenetic mechanisms. This hypothesis was strengthened by the preferential localization of the downregulated IC receptors in predefined hotspots for histone remodeling.

Histone deacetylase (HDAC) enzymes modulate maturation, migration, and TCR signaling in $\mathrm{T}$ cells by mediating the expression of essential transcription factors such as Tcf1 and Lef1 $(32,33)$. Treatment with HDACi enhances the antitumor activity of cytotoxic $\mathrm{T}$ cells in different tumor types (34). In addition, HDACi directly acts on tumor cells by upregulating MHC class I molecules and indirectly by eliminating myeloid-derived suppressor cells (35). Notably, HDACis can increase the expression of immune-related molecules in different cancer types $(36,37)$. In our study, treatment with HDACi increased the gene expression of defined IC receptors mainly in AML BM-infiltrating $\mathrm{CD}^{+} \mathrm{T}$ cells and partially in $\mathrm{CD} 4^{+} \mathrm{T}$ cells.

Several studies have demonstrated that treatment with HDACi dampens the anti-tumor immune response by upregulation of PD-1 on T cells $(38,39)$. Thus, PD-1/PD-L1 blocking antibodies and HDACis have synergistic effects in the treatment of different cancers $(38,39)$. Additionally, VPA treatment blocked the function of myeloid-derived suppressor cells and made tumor cells susceptible to anti-PD-L1 immunotherapy (40). Similarly, treatment with HDACi in our study resulted in an upregulation of PDCD1 in $\mathrm{CD} 8^{+} \mathrm{T}$ cells, suggesting an increased vulnerability to treatment with ICIs

The phosphatase PAC1 was recently identified as an important mediator of $\mathrm{T}$ cell dysfunction in tumor infiltrating lymphocytes (TILs) that act via histone deacetylation to reshape chromatin accessibility during activation of effector T cells (13). We observed a negative correlation of $P A C 1$ expression with the expression of the downregulated ICs in AML BM-infiltrating $\mathrm{CD}^{+} \mathrm{T}$ cells. Silencing of $P A C 1$ resulted in the upregulation of different ICs and enhanced the expression of $\mathrm{CD}^{+} \mathrm{T}$ cell effector molecules.

In summary, our results indicate that $\mathrm{CD}^{+} \mathrm{T}$ cells in $\mathrm{AML}$ are dysfunctional due to a downregulation of activating IC receptors rather than due to signaling by immune inhibitory IC receptors. These findings may explain the limited efficacy of antibodies that block immune-inhibitory ICs. Therefore, treatment with HDACi or targeting of T cell-specific epigenetic modulators may stimulate anti-tumor immunity by increasing $\mathrm{CD}^{+} \mathrm{T}$ cell effector function in leukemia patients and restore the susceptibility to treatment with IC blocking agents.

\section{REFERENCES}

1. Riether C, Schurch CM, Ochsenbein AF. Regulation of hematopoietic and leukemic stem cells by the immune system. Cell Death Differ (2015) 22 (2):187-98. doi: 10.1038/cdd.2014.89

2. Hope KJ, Jin L, Dick JE. Acute myeloid leukemia originates from a hierarchy of leukemic stem cell classes that differ in self-renewal capacity. Nat Immunol (2004) 5(7):738-43. doi: 10.1038/nil080

3. Geerman S, Brasser G, Bhushal S, Salerno F, Kragten NA, Hoogenboezem M, et al. Memory CD8(+) T cells support the maintenance of hematopoietic stem

\section{DATA AVAILABILITY STATEMENT}

All transcriptomic data compiled for this study have been deposited in NCBI GEO under the accession codes: GSE117090.

\section{ETHICS STATEMENT}

The studies involving human participants were reviewed and approved by the local ethical committee (Kantonale Ethikkommission Bern, KEK122/14). The patients/participants provided their written informed consent to participate in this study.

\section{AUTHOR CONTRIBUTIONS}

RR designed and performed experiments, analyzed and interpreted data, and wrote the manuscript. MS performed the experiments. CR designed the experiments and interpreted data. AO designed experiments, interpreted data, wrote the manuscript, and supervised the project. All authors contributed to the article and approved the submitted version.

\section{FUNDING}

This work was supported by grants from the Werner und Hedy Berger-Janser Stiftung, Swiss National Science Foundation and the Stiftung für klinisch-experimentelle Tumorforschung (Bern).

\section{ACKNOWLEDGMENTS}

We thank the staff of the genomic facility of Basel University, the Department of Biosystems Science and Engineering (D-BSSE, Basel, Switzerland), and the flow cytometry facility (FACSlab, University Bern, Switzerland) for providing technical assistance.

\section{SUPPLEMENTARY MATERIAL}

The Supplementary Material for this article can be found online at: https://www.frontiersin.org/articles/10.3389/fonc.2021. 663406/full\#supplementary-material

cells in the bone marrow. Haematologica (2018) 103(6):e230-3. doi: 10.3324/ haematol.2017.169516

4. Jaiswal S, Jamieson CH, Pang WW, Park CY, Chao MP, Majeti R, et al. CD47 is upregulated on circulating hematopoietic stem cells and leukemia cells to avoid phagocytosis. Cell (2009) 138(2):271-85. doi: 10.1016/j.cell.2009.05.046. S0092-8674(09)00651-5.

5. Lesokhin AM, Callahan MK, Postow MA, Wolchok JD. On being less tolerant: enhanced cancer immunosurveillance enabled by targeting checkpoints and agonists of T cell activation. Sci Transl Med (2015) 7 (280):280sr1. doi: 10.1126/scitranslmed.3010274 
6. Forster S, Radpour R. Molecular Immunotherapy: Promising Approach to Treat Metastatic Colorectal Cancer by Targeting Resistant Cancer Cells or Cancer Stem Cells. Front Oncol (2020) 10:569017. doi: 10.3389/fonc.2020.569017

7. Pardoll DM. The blockade of immune checkpoints in cancer immunotherapy. Nat Rev Cancer (2012) 12(4):252-64. doi: 10.1038/nrc3239

8. Vago L, Gojo I. Immune escape and immunotherapy of acute myeloid leukemia. J Clin Invest (2020) 130(4):1552-64. doi: 10.1172/jci129204

9. Brück O, Dufva O, Hohtari H, Blom S, Turkki R, Ilander M, et al. Immune profiles in acute myeloid leukemia bone marrow associate with patient age, Tcell receptor clonality, and survival. Blood Adv (2020) 4(2):274-86. doi: 10.1182/bloodadvances.2019000792

10. Dufva O, Pölönen P, Brück O, Keränen MAI, Klievink J, Mehtonen J, et al. Immunogenomic Landscape of Hematological Malignancies. Cancer Cell (2020) 38(3):380-99.e13. doi: 10.1016/j.ccell.2020.06.002

11. Stahl M, Goldberg AD. Immune Checkpoint Inhibitors in Acute Myeloid Leukemia: Novel Combinations and Therapeutic Targets. Curr Oncol Rep (2019) 21(4):37. doi: 10.1007/s11912-019-0781-7

12. Radpour R, Riether C, Simillion C, Hopner S, Bruggmann R, Ochsenbein AF. CD8(+) T cells expand stem and progenitor cells in favorable but not adverse risk acute myeloid leukemia. Leukemia (2019) 33(10):2379-92. doi: 10.1038/ s41375-019-0441-9

13. Dan L, Liu L, Sun Y, Song J, Yin Q, Zhang G, et al. The phosphatase PAC1 acts as a $\mathrm{T}$ cell suppressor and attenuates host antitumor immunity. Nat Immunol (2020) 21(3):287-97. doi: 10.1038/s41590-019-0577-9.

14. Zeng Z, Wei F, Ren X. Exhausted T cells and epigenetic status. Cancer Biol Med (2020) 17(4):923-36. doi: 10.20892/j.issn.2095-3941.2020.0338

15. Yoshikawa Y, Kuribayashi K, Minami T, Ohmuraya M, Kijima T. Epigenetic Alterations and Biomarkers for Immune Checkpoint Inhibitors-Current Standards and Future Perspectives in Malignant Pleural Mesothelioma Treatment. Front Oncol (2020) 10:554570. doi: 10.3389/fonc.2020.554570

16. Wrangle J, Wang W, Koch A, Easwaran H, Mohammad HP, Vendetti F, et al. Alterations of immune response of Non-Small Cell Lung Cancer with Azacytidine. Oncotarget (2013) 4(11):2067-79. doi: 10.18632/ oncotarget.1542

17. Yang H, Bueso-Ramos C, DiNardo C, Estecio MR, Davanlou M, Geng QR, et al. Expression of PD-L1, PD-L2, PD-1 and CTLA4 in myelodysplastic syndromes is enhanced by treatment with hypomethylating agents. Leukemia (2014) 28(6):1280-8. doi: 10.1038/leu.2013.355

18. Daver N, Garcia-Manero G, Basu S, Boddu PC, Alfayez M, Cortes JE, et al. Efficacy, Safety, and Biomarkers of Response to Azacitidine and Nivolumab in Relapsed/Refractory Acute Myeloid Leukemia: A Nonrandomized, OpenLabel, Phase II Study. Cancer Discov (2019) 9(3):370-83. doi: 10.1158/21598290.Cd-18-0774

19. Zhang L, Gajewski TF, Kline J. PD-1/PD-L1 interactions inhibit antitumor immune responses in a murine acute myeloid leukemia model. Blood (2009) 114(8):1545-52. doi: 10.1182/blood-2009-03-206672

20. Riether C, Gschwend T, Huguenin AL, Schurch CM, Ochsenbein AF. Blocking programmed cell death 1 in combination with adoptive cytotoxic T-cell transfer eradicates chronic myelogenous leukemia stem cells. Leukemia (2015) 29(8):1781-5. doi: 10.1038/leu.2015.26

21. Mumprecht S, Schürch C, Schwaller J, Solenthaler M, Ochsenbein AF. Programmed death 1 signaling on chronic myeloid leukemia-specific T cells results in T-cell exhaustion and disease progression. Blood (2009) 114 (8):1528-36. doi: 10.1182/blood-2008-09-179697

22. Herrmann M, Krupka C, Deiser K, Brauchle B, Marcinek A, Ogrinc Wagner A, et al. Bifunctional PD-1 $\mathrm{x}$ alphaCD3 $\mathrm{x}$ alphaCD33 fusion protein reverses adaptive immune escape in acute myeloid leukemia. Blood (2018) 132 (23):2484-94. doi: 10.1182/blood-2018-05-849802

23. Williams P, Basu S, Garcia-Manero G, Hourigan CS, Oetjen KA, Cortes JE, et al. The distribution of T-cell subsets and the expression of immune checkpoint receptors and ligands in patients with newly diagnosed and relapsed acute myeloid leukemia. Cancer (2019) 125(9):1470-81. doi: $10.1002 / \mathrm{cncr} .31896$

24. Zhang CC. Hematopoietic stem cells: interplay with immunity. Am J Blood Res (2012) 2(4):219-27.

25. Pistillo MP, Tazzari PL, Palmisano GL, Pierri I, Bolognesi A, Ferlito F, et al. CTLA-4 is not restricted to the lymphoid cell lineage and can function as a target molecule for apoptosis induction of leukemic cells. Blood (2003) 101 (1):202-9. doi: 10.1182/blood-2002-06-1668

26. Riether C, Schurch CM, Flury C, Hinterbrandner M, Druck L, Huguenin AL, et al. Tyrosine kinase inhibitor-induced CD70 expression mediates drug resistance in leukemia stem cells by activating Wnt signaling. Sci Transl Med (2015) 7(298):298ra119. doi: 10.1126/scitranslmed.aab1740

27. Baessler T, Krusch M, Schmiedel BJ, Kloss M, Baltz KM, Wacker A, et al. Glucocorticoid-induced tumor necrosis factor receptor-related protein ligand subverts immunosurveillance of acute myeloid leukemia in humans. Cancer Res (2009) 69(3):1037-45. doi: 10.1158/0008-5472.CAN-08-2650

28. Kikushige Y, Miyamoto T, Yuda J, Jabbarzadeh-Tabrizi S, Shima T, Takayanagi S, et al. A TIM-3/Gal-9 Autocrine Stimulatory Loop Drives Self-Renewal of Human Myeloid Leukemia Stem Cells and Leukemic Progression. Cell Stem Cell (2015) 17 (3):341-52. doi: 10.1016/j.stem.2015.07.011

29. Zhang Y, Zheng J. Functions of Immune Checkpoint Molecules Beyond Immune Evasion. Adv Exp Med Biol (2020) 1248:201-26. doi: 10.1007/978981-15-3266-5_9

30. He X, Xu C. Immune checkpoint signaling and cancer immunotherapy. Cell Res (2020) 30(8):660-9. doi: 10.1038/s41422-020-0343-4

31. Saleh R, Toor SM, Sasidharan Nair V, Elkord E. Role of Epigenetic Modifications in Inhibitory Immune Checkpoints in Cancer Development and Progression. Front Immunol (2020) 11:1469. doi: 10.3389/ fimmu.2020.01469

32. Haery L, Thompson RC, Gilmore TD. Histone acetyltransferases and histone deacetylases in B- and T-cell development, physiology and malignancy. Genes Cancer (2015) 6(5-6):184-213. doi: 10.18632/genesandcancer.65

33. Xing S, Li F, Zeng Z, Zhao Y, Yu S, Shan Q, et al. Tcfl and Lef1 transcription factors establish CD8(+) T cell identity through intrinsic HDAC activity. Nat Immunol (2016) 17(6):695-703. doi: 10.1038/ni.3456

34. Bae J, Hideshima T, Tai YT, Song Y, Richardson P, Raje N, et al. Histone deacetylase (HDAC) inhibitor ACY241 enhances anti-tumor activities of antigen-specific central memory cytotoxic $\mathrm{T}$ lymphocytes against multiple myeloma and solid tumors. Leukemia (2018) 32(9):1932-47. doi: 10.1038/ s41375-018-0062-8

35. Sun T, Li Y, Yang W, Wu H, Li X, Huang Y, et al. Histone deacetylase inhibition up-regulates MHC class I to facilitate cytotoxic T lymphocytemediated tumor cell killing in glioma cells. J Cancer (2019) 10(23):5638-45. doi: $10.7150 /$ jca. 34471

36. Burke B, Eden C, Perez C, Belshoff A, Hart S, Plaza-Rojas L, et al. Inhibition of Histone Deacetylase (HDAC) Enhances Checkpoint Blockade Efficacy by Rendering Bladder Cancer Cells Visible for T Cell-Mediated Destruction. Front Oncol (2020) 10:699. doi: 10.3389/fonc.2020.00699

37. Chen IC, Sethy B, Liou JP. Recent Update of HDAC Inhibitors in Lymphoma. Front Cell Dev Biol (2020) 8:576391. doi: 10.3389/fcell.2020.576391

38. Kim YD, Park SM, Ha HC, Lee AR, Won H, Cha H, et al. HDAC Inhibitor, CG-745, Enhances the Anti-Cancer Effect of Anti-PD-1 Immune Checkpoint Inhibitor by Modulation of the Immune Microenvironment. J Cancer (2020) 11(14):4059-72. doi: 10.7150/jca.44622

39. Que Y, Zhang XL, Liu ZX, Zhao JJ, Pan QZ, Wen XZ, et al. Frequent amplification of HDAC genes and efficacy of HDAC inhibitor chidamide and PD-1 blockade combination in soft tissue sarcoma. J Immunother Cancer (2021) 9(2):e001696. doi: 10.1136/jitc-2020-001696

40. Adeshakin AO, Yan D, Zhang M, Wang L, Adeshakin FO, Liu W, et al. Blockade of myeloid-derived suppressor cell function by valproic acid enhanced anti-PD-L1 tumor immunotherapy. Biochem Biophys Res Commun (2020) 522(3):604-11. doi: 10.1016/j.bbrc.2019.11.155

Conflict of Interest: The authors declare that the research was conducted in the absence of any commercial or financial relationships that could be construed as a potential conflict of interest.

Copyright $\odot 2021$ Radpour, Stucki, Riether and Ochsenbein. This is an open-access article distributed under the terms of the Creative Commons Attribution License (CC BY). The use, distribution or reproduction in other forums is permitted, provided the original author(s) and the copyright owner(s) are credited and that the original publication in this journal is cited, in accordance with accepted academic practice. No use, distribution or reproduction is permitted which does not comply with these terms. 